\title{
Estimate of the Arctic Convective Boundary Layer Height from Lidar Observations: A Case Study
}

\author{
L. Di Liberto, ${ }^{1}$ F. Angelini, ${ }^{1}$ I. Pietroni, ${ }^{1}$ F. Cairo, ${ }^{1}$ G. Di Donfrancesco, ${ }^{2}$ A. Viola, ${ }^{1}$ \\ S. Argentini, ${ }^{1}$ F. Fierli, ${ }^{1}$ G. Gobbi, ${ }^{1}$ M. Maturilli, ${ }^{3}$ R. Neuber, ${ }^{3}$ and M. Snels ${ }^{1}$ \\ ${ }^{1}$ Institute for Atmospheric Sciences and Climate, CNR, 00133 Rome, Italy \\ ${ }^{2}$ ENEA UTA, Santa Maria di Galeria, 00123 Rome, Italy \\ ${ }^{3}$ Alfred Wegener Institute for Polar and Marine Research, 14473 Potsdam, Germany
}

Correspondence should be addressed to L. Di Liberto, 1.diliberto@isac.cnr.it

Received 16 November 2011; Revised 18 January 2012; Accepted 19 January 2012

Academic Editor: Igor N. Esau

Copyright (C) 2012 L. Di Liberto et al. This is an open access article distributed under the Creative Commons Attribution License, which permits unrestricted use, distribution, and reproduction in any medium, provided the original work is properly cited.

\begin{abstract}
A new automated small size lidar system (microlidar or MULID) has been developed and employed to perform aerosol measurements since March 2010 at Ny Ålesund $\left(78.9^{\circ} \mathrm{N}, 11.9^{\circ} \mathrm{E}\right)$, Svalbard. The lidar observations have been used to estimate the PBL height by using the gradient method based on abrupt changes in the vertical aerosol profile and monitor its temporal evolution. The scope of the present study is to compare several approaches to estimate the PBL height, by using lidar observations, meteorological measurements by radio soundings, and a zero-order one-dimensional model based on a parameterization of the turbulent kinetic energy budget within the mixing layer, under the assumptions of horizontal homogeneity, and neglecting radiation and latent heat effects. A case study is presented here for a convective PBL, observed in June 2010 in order to verify whether the Gradient Method can be applied to lidar measurements in the Arctic region to obtain the PBL height. The results obtained are in good agreement with the PBL height estimated by the analysis of thermodynamic measurements obtained from radio sounding and with the model.
\end{abstract}

\section{Introduction}

There is no region on Earth where the climate is changing faster than in the Arctic. Recent studies show that processes in the lower atmosphere are critical for a proper understanding and modelling of Arctic climate change [1-3]. The reliability of climate models is often poor in Arctic regions because the parameterizations of the planetary boundary layer (PBL) are mainly based on observations at lower latitudes.

A proper characterization of the Arctic PBL processes, including the exchange of momentum, heat, moisture, and chemical species between the surface and the free troposphere, is needed for a better understanding of the forcings that drive the changes going on in these regions.

In this context the PBL height is an important parameter as it allows to define a scale on which several processes in the Arctic PBL occur.

In spite of the importance of proper monitoring the vertical development of the PBL (which is also a key parameter in mesoscale climate models), no unique method exists to determine its height [4]. In fact, the evaluation of the PBL height can be performed by using a variety of methods, based on the analysis of thermodynamic variables, on turbulence-related parameters or by measuring concentrations of tracers. According to [4], the measurement of tracers concentration is the only direct method allowing the estimate of the PBL height under stable conditions as in such conditions the thermodynamic approach is neither reliable nor well defined.

Atmospheric aerosols represent often a good tracer for this purpose. It is produced at ground and mixed within the PBL through turbulence processes. If no advection/removal of aerosol occurs in the PBL, the concentration profile of aerosols can be assumed as a reliable proxy for the PBL height.

The evaluation of the aerosol burden in the Arctic PBL is not only useful to provide an estimation of PBL dynamics, but also valuable in itself since the presence of aerosol in the planetary boundary layer influences the energy budget and hence the climate in several ways. 
It is widely accepted that the aerosol concentrations in Arctic are lower than at midlatitude, thereby making the system more sensitive to climate changes; due to a low back ground concentration, even a small increase can be observed and is significant in terms of climate change $[5,6]$. There are indications of important local sources inside the pack ice that rely on biogenic processes in the ice and in open leads. These may be very susceptible to change through a global warming. Moreover, transport of aerosols from the midlatitudes has been observed in the Arctic in the last 10 years, and its impact has been investigated [7].

According to recent calculations using Global Circulation Models (e.g., [8]), aerosol particles may have a cooling effect at the Earth surface, smaller but possibly comparable to the warming effect due to the increased concentration of anthropogenic greenhouse gases in the atmosphere. However, in the case of snow-covered surfaces, the effect of black carbon deposited on the surface may counteract the predicted cooling through a reduction of the surface albedo [9]. These opposite effects make the arctic changes an extremely unpredictable scenario [10].

The structure and dynamics of the majority of the aerosols present in the PBL are strongly influenced by the surface energy fluxes. Especially in snow-covered regions, the deposition of aerosol on the surface primarily leads to a reduction of the albedo, and consequently to the heat amount absorbed by the soil. The concentration of aerosols may also affect the melting/freezing of the Arctic sea ice ([11, 12]).

To provide both a characterization of PBL dynamics and a monitoring of aerosol burden in the Arctic lower troposphere, a microlidar has been installed in Ny Ålesund $\left(78.9^{\circ} \mathrm{N}, 11.9^{\circ} \mathrm{E}\right)$, Svalbard, Norway, in 2010 and has been operating since then, in the framework of a collaboration between the Italian Consiglio Nazionale delle Ricerche (CNR) and the German Alfred Wegener Institute (AWI). Ny Ålesund represents a unique site where a large international cooperation granted the deployment of an ample set of instruments for monitoring a large number of key parameters of the Arctic system. Ny Ålesund is situated on the south side of the deep and sheltered Kongsfjord on the west coast of the Svalbard archipelago. The fjord is enclosed by glaciers on one side and by the Zeppelin mountain ( $473 \mathrm{~m}$ a.s.l.) south of the town.

In the framework of the Climate Change Tower-Integrated Project (CCT-IP), an instrumented meteotower $(32 \mathrm{~m}$ high) has been deployed in Ny Ålesund in the year 2009, complemented by a number of other in situ and remote sensing devices for the characterization of the Arctic surface and lower troposphere. The small-sized, portable, and automated micro-LIDAR (LIght Detection And Ranging), MULID, has been installed at the AWI Koldewey station and has been providing high-resolution profiles of the aerosol vertical distribution and optical properties from the ground up to about $3000 \mathrm{~m}$, since March 2010. The system is a zenith-pointing Rayleigh (elastic) lidar, operating at $532 \mathrm{~nm}$, providing also the volume depolarization that gives qualitative information on the shape of the scattering particles $[13,14]$.

In the present work we analyse a case study in order to test the applicability of the aerosol vertical profiles as tracers in the determination of the PBL height at the Svalbard site. The chosen case (14 June 2010) is characterised by low wind speed, and the PBL shows evident convective characteristics. The method is inadequate when the PBL height is extremely low (below $50 \mathrm{~m}$ ), or when the PBL is not well mixed, as occurs in strong wind conditions.

Furthermore, both LIDAR profiles and ancillary data are available for the whole day, and the aerosol concentration is large enough to allow the use of the aerosol backscatter profiles to estimate the PBL height. The PBL height is also determined by using meteorological measurements from collocated simultaneous radio sounding, and by applying the zero-order one-dimensional model proposed by Gryning [15]. The aim of this work is to understand to what extent the lidar-based technique can be adopted in future campaigns, combining the lidar technique with other complementary methods such as SODAR RASS, Models, Soundings, WindProfiling Radars in order to obtain reliable values for the PBL height in this region. Some techniques are described in [1618].

The paper is organized as follows: in Section 2, the instruments and methods used in our work are presented. A discussion of the results is presented in Section 3, and the comparison between observations and the $1 \mathrm{D}$ prognostic model is shown in order to evaluate the accuracy of the PBL height obtained from the lidar data. Finally, in Section 4 conclusions will be drawn.

\section{Instruments and Methods}

2.1. Micro-Lidar (MULID). The lidar system has been developed in the laboratories of the Institute of Atmospheric Science and Climate of CNR, (ISAC-CNR). It is contained inside a thermally insulated, fiberglass, and polystyrene box. The temperature in the box is controlled by three $30 \mathrm{~W}$ heaters, and two fans mainly dedicated to keep the system temperature at operating conditions. An external blower with a laminar diffuser continuously cleans the glass window on the top of the system. The Lidar system [19] is shown in Figure 1.

The laser source is a compact size, low-weight diode pumped Nd:YAG laser (Laser-Compact group), with secondharmonic generation and active $\mathrm{Q}$ switching. The laser pulse duration is less than $10 \mathrm{~ns}$ and the output energy is $29 \mu \mathrm{J} /$ pulse at $532 \mathrm{~nm}$ and $25 \mu \mathrm{J} /$ pulse at $1064 \mathrm{~nm}$. The pulse repetition rate is $1 \mathrm{kHz}$, with a beam divergence at $532 \mathrm{~nm}$ of less than $1.5 \mathrm{mrad}$ which is reduced by a beam expander to $0.2 \mathrm{mrad}$. The laser system has a maximum power consumption of $100 \mathrm{~W}$ ( $60 \mathrm{~W}$ Laser Head and $40 \mathrm{~W}$ Power Supply Unit).

The receiving optics is composed of a Newtonian $20 \mathrm{~cm}$ diameter $\mathrm{f} / 1.5$ telescope, with a full Field of View (FOV) of $1.3 \mathrm{mrad}$ set by a field stop of 400 micron. The laser is mounted in a quasiparallel geometry, causing intersection with the telescope FOV at about $50 \mathrm{~m}$ reaching full overlap at $150 \mathrm{~m}$. A polarizing beam-splitter cube is used to separate the $532 \mathrm{~nm}$ signal collected by the telescope into two polarized components, respectively, parallel and perpendicular to the laser emission. The radiation is then focused onto miniaturized 


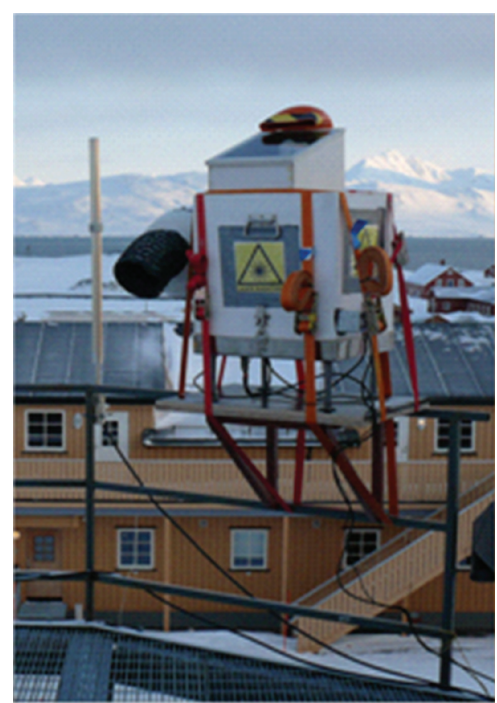

(a)

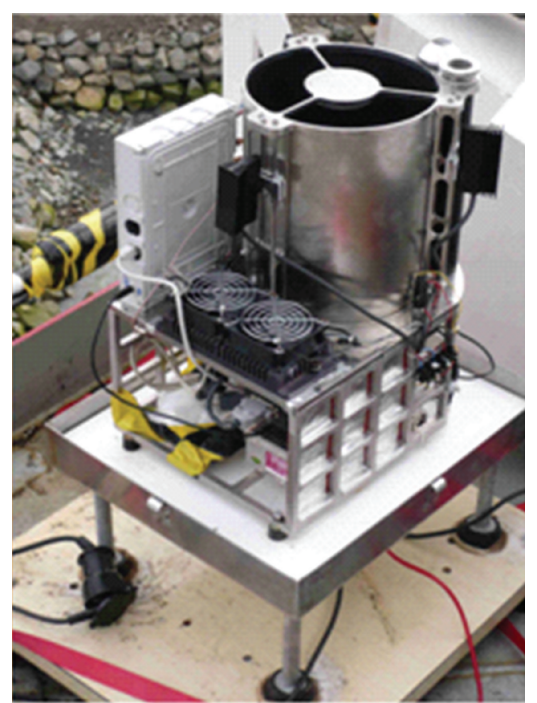

(b)

FIgURE 1: In (a) the micro-lidar (MULID) on the roof of the AWI station at Ny Ålesund $\left(78.9^{\circ} \mathrm{N}, 11.978 .9^{\circ} \mathrm{N}, 11.9^{\circ} \mathrm{E}\right)$, Svalbard. In $(\mathrm{b})$ the optical and electronic components of the system.

photomultiplier modules (Hamamatsu 5783P) with very low thermal noise (below 10 counts $/ \mathrm{s}$ at $25^{\circ} \mathrm{C}$ ). The PMT signal is recorded both in current mode and in photon counting mode. In the current mode the time resolution of the $\mathrm{AD}$ $(80 \mathrm{MHz})$ converter allows a vertical resolution of $1.875 \mathrm{~m}$ over a $1.875 \mathrm{~km}$ range, while in photon counting mode the time resolution (100 ns) allows a vertical resolution of $15 \mathrm{~m}$ and a range of $15 \mathrm{~km}$. These parameters can be varied to reduce the vertical resolution to $15 \mathrm{~m}$ and $75 \mathrm{~m}$, respectively, and to increase the range to $15 \mathrm{~km}$ and $75 \mathrm{~km}$, respectively, in case a coarser and more extended profile reconstruction is needed.

The system capability to work unattended for long periods has allowed continuous operation (24/24) delivering 5minute averaged profiles every half hour. In special observing periods, like in the springtime, when vertical profiles of meteorological parameters were simultaneously obtained by using different sondes operated from a tethered balloon by AWI, a higher temporal resolution has been set, providing continuous time series of profiles.

2.1.1. Gradient Method. The height of the PBL may be estimated by lidar measurements by investigating the vertical profile of the aerosol backscatter signal. Several approaches have been proposed in the literature for determining the PBL height from Rayleigh-Mie lidar measurements. One method which is frequently used with low power lidars is based on the determination of the inflection points of the profile. The aerosol backscatter signal depends on the aerosol numerical concentration, and in a rather complicated way also on aerosol size, shape, and composition. If the size, shape, and composition can be considered uniform in space, the volume aerosol backscatter coefficient, determined from the lidar measurements can be considered linearly proportional to the aerosol number concentration. Generally the aerosol concentration decreases sharply at the transition between the PBL and the free troposphere. This variation, observed as a sharp decrease of the aerosol backscatter cross section, may be used to determine the PBL height. The amount of the variation depends on the aerosol type, concentration, and the wavelength employed [20]. Since this approach is based on finding the maxima of the first derivative of the signal, this method, described by Endlich et al. [21], is called "gradient method." Other approaches employ the absolute value of the aerosol cross-section [22] and define the top of the PBL as the lowest point where the backscatter ratio falls below a threshold value. This is based on the assumption that in the free troposphere the aerosol concentration is very low. The main drawback of this method is that the inversion of the lidar profile is required, and a high signal-to-noise ratio is necessary to avoid false attributions. A third method, the so-called variance method, is based on the analysis of the temporal behaviour of the variance of the signal at each altitude. It represents a very powerful approach to detect the convective boundary layer, since the turbulence inside the mixing layer and the entrainment zone leads to very variable concentration of tracers, resulting in a highly variable aerosol cross-section. On the other hand, stable boundary layers are not easy to detect in this way thus restricting most of these studies to the daytime observations [23-26]. Obviously, all these methods are valid under the assumption that no aerosol advection or removal from the PBL is occurring.

The appeal of the gradient method resides in the fact that it neither requires to perform a full inversion of the profile, nor does it take into account corrections for beam-FOV overlap $[27,28]$. Often inflection points are determined in the background subtracted range corrected signal (RCS), or, in alternative, its logarithm.

In order to find the inflection points, which are needed while using the gradient method, two different strategies are 


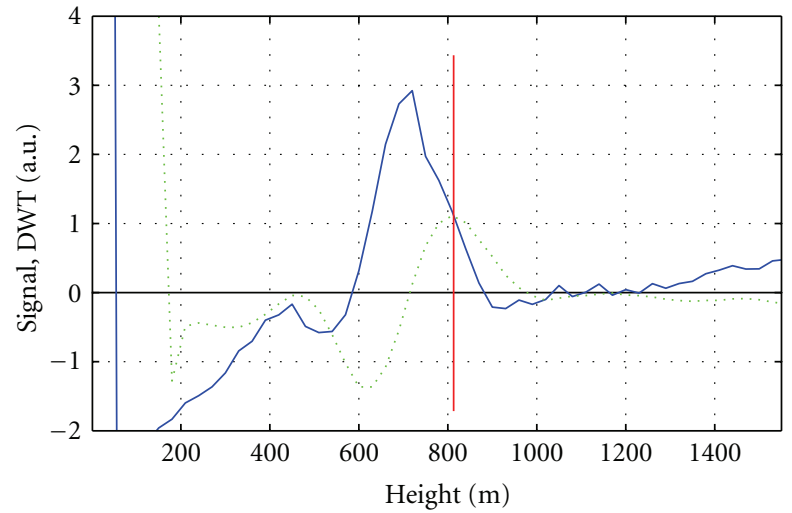

Figure 2: The logarithmic Range-Corrected Signal (blue) and its Discrete Wavelet Transform (green) of the profile around 9:00 UTC. The DWT is calculated with a Haar function of $150 \mathrm{~m}$ width. The red line is set at the height corresponding to the first maximum of the DWT exceeding the threshold of 0.5 and represents the estimate of the PBL height at that moment. This threshold is the only parameter to be tuned in the wavelet analysis.

possible: the first is based on the direct numerical differentiation, while the second employs the so-called Discrete Wavelet Transform (DWT), using a zero-order wavelet (Haar function). This DWT consists in the convolution product of the signal (either range-corrected or logarithmic range-corrected) with a finite-size step function. The method is well described, for example, in $[29,30]$.

Where the signal is "in phase" with the Haar wavelet, the convolution product shows a maximum, and an inflection point is found. The maxima of this DWT can then be used to determine the inflection points of the RCS. The advantage of the DWT is that, being based on an integral quantity instead of a derivative, it is much less prone to noise-induced detections than the numerical differentiation. Another advantage of the DWT technique is that, changing the dilation of the Haar function, a multiscale analysis [31] can be easily performed. On the other hand, it should be stressed that the width of the Haar function affects the minimum height at which the retrieval of inflection points is possible. In fact, the DWT is only defined above the centre of the wavelet. Hence, it is fundamental to choose the dilation of the wavelet coherently with the scale of the structures we expect to observe. This is visible in Figure 2, where the logarithmic RCS (blue) and its DWT (green) are shown for one lidar profile. There, the red line is set at the height where the first maximum of the DWT has exceeded a threshold value of 0.5 . That height in fact represents the estimate of the PBL height. The threshold value is the only parameter to be tuned in the wavelet analysis; its value in the present analysis has been chosen according to Haij et al. [31].

Once the aerosol layers have been identified with the gradient method (by DWT or direct differentiation), a problem of attribution still remains, since multiple aerosol layers can simultaneously be present in the vertical profile [20] leaving the correct identification of the actual PBL height still an open task. A very popular criterion is to choose the lowest maximum whose first derivative is above the threshold ([31] and reference there in).

2.2. PBL Height from Radiosonde Data. Atmospheric soundings by Vaisala RS92 radio sondes are carried out at Ny Ålesund once a day at 12 UTC, providing profiles of pressure, temperature, relative humidity, wind speed, and wind direction from ground to about $30 \mathrm{~km}$, with a vertical resolution of a few metres depending on the balloon ascending speed.

The sondes are carried by helium-filled balloons (TOTEX TX600, or TX800), and data reception and evaluation are provided by a DigiCora System (VAISALA). The data is coded (FM35-Temp) and transferred to the Global Telecommunication System (GTS).

\subsubsection{Lapse Rate Method and Richardson Bulk Method. Since} the convective PBL is characterised by deep mixing of thermodynamic quantities, their gradients are expected to be very small. The inversion present on top of the convective PBL shows significant gradients in potential temperature and relative humidity, towards the warmer and drierfree atmosphere. A method for the determination of the PBL height from radiosonde or balloon observations is based on the computation of the vertical gradients in potential temperature and/or relative humidity [32]. The algorithm of Hayden et al. [33] detects PBL height as the first level at which the vertical gradient in potential temperature exceeds $2 \mathrm{~K} / \mathrm{km}$ and the vertical gradient in $\mathrm{RH}<0 \% / \mathrm{km}$. This kind of method is commonly called the lapse rate method, because the PBL height is defined when a determined value or a combination of determined values of lapse rates in atmospheric variables is met.

Another commonly used method which is suitable for sta-ble as well as for unstable conditions is the Richardson bulk method [23, 34-36]. The Richardson number is a scaling parameter that indicates the ratio of thermal and mechanical production of turbulence. It has a characteristic behaviour for the mixing layer and the free atmosphere on top of it.

The Richardson bulk number $R_{i b}$ is calculated as

$$
R_{i b}(z)=g \frac{\left(z-z_{0}\right)\left[\vartheta(z)-\vartheta\left(z_{0}\right)\right]}{\vartheta(z)\left[u^{2}(z)-v^{2}(z)\right]}
$$

with $g$ the gravity constant of $9.81 \mathrm{~m} / \mathrm{s}^{2}, z$ and $z_{0}$ represent altitude and the lowest level of observation, respectively. Furthermore, $\vartheta=T\left(P_{0} / P\right)^{R_{d} / c_{p}}$ denotes potential temperature and $u(z)$ and $v(z)$ are the zonal and meridional components of the wind vector, respectively. The numerator represents the buoyancy term, in which the rising of the thermal potential is described. The denominator contains information about wind shear. Here it is assumed that the wind speed at $z_{0}$ is zero.

The PBL height can be defined as the height of the first level at which the Richardson bulk number exceeds a certain threshold value, such that $R_{i b}>R_{i b c}[36,37]$. A common value for $R_{i b c}$ reported in the literature is 0.21 . Beyond this critical value of $R_{i b}$ the atmosphere can be considered fully 
decoupled from the PBL. In other studies reported by Troen and Mahrt [38], $R_{i b c}$ reaches the critical value of 0.25 .

2.3. Batcharova and Gryning Model. Several models have been proposed to estimate the PBL height under convective conditions. Among these a simple one-dimensional prognostic model proposed by Gryning and Batcharova [15] was used in various studies both in mid and high latitudes. The results obtained in harsh climate [39] encouraged the use of this model for the Ny Ålesund dataset. The model is based on a parametrization of the turbulent kinetic energy budget within the mixing layer, assuming horizontal homogeneity, and neglecting radiation and latent heat effects [40]. In the derivation of the model the entrainment zone is idealized as infinitesimally thin (zero order scheme). The final practical and prognostic equation for the height evolution is the following $[15,40]$ :

$$
\begin{aligned}
& \left\{\left(\frac{h^{2}}{(1+A) h-2 B k L}\right)+\frac{C u_{*}^{2} T}{\gamma g[(1+A) h-B k L]}\right\}\left(\frac{d h}{d t}-w_{s}\right) \\
& =\frac{\left(\overline{w^{\prime} \vartheta^{\prime}}\right)_{s}}{\gamma},
\end{aligned}
$$

where $h$ is the PBL height, $k$ is the von Karman constant $(k=$ $0.41), L$ is the Obukhov length, $u_{*}$ is the friction velocity, $T$ is the surface temperature, $g$ is the acceleration due to gravity, $\left(\overline{w^{\prime} \vartheta^{\prime}}\right)$ is the kinematic heat flux at the surface, $\gamma$ is the potential temperature gradient in the free atmosphere, $w_{s}$ is the negative of the subsidence velocity, and $A, B$, and $C$ are empirical constants set to $0.2,2.5$ and 8 , respectively [41].

The first two terms on the left side of (2) represent the entrainment due to buoyancy and mechanical turbulence, and the so-called spin-up effect, respectively. The latter is active during the morning, when the PBL height is small and its growth rate is controlled by the friction velocity. In the central part of the day this contribution decreases and the turbulent flux influences the development of the PBL [15].

Equation (2) was solved numerically with an initial guess value of $\mathrm{h}$ set at $30 \mathrm{~m}$ and a time step of 10 minutes.

The turbulent parameters, namely, $u_{*},\left(\overline{\bar{w}^{\prime} \vartheta^{\prime}}\right)_{s}$ and $L$, were derived from the sonic anemometer (Gill R50 Solent) data using the eddy covariance technique [42]. Two rotations have been applied to correct the measurements for possible sensor tilt errors.

The two external parameters $\gamma$, and $w_{s}$ present in (2) have been estimated as described in Section 3.

The subsidence $w_{s}$ represents the mean vertical motion of the air at the top of the boundary layer. It can be estimated if the horizontal divergence of the large-scale flow is known as function of height. When the horizontal divergence is constant with height, the subsidence is proportional to the divergence. The latter can be estimated if wind measurements from a network of meteorological stations are available [15].

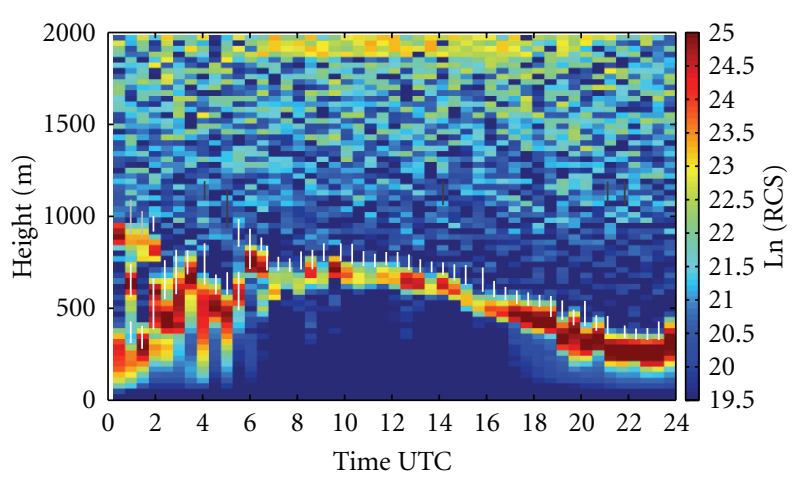

FIgure 3: The natural logarithm of the RCS at $532 \mathrm{~nm}$ (parallel polarization). The higher the ln (RCS), the larger the aerosol crosssection. This can be due to larger particles (i.e., cloud droplets or rain) as well as higher numerical particle concentration. Gray and white bars represent the top of aerosol stratifications. The PBL height can be assigned to one of these aerosol layers. The length of the lines represent their indetermination.

\section{Discussion}

The lidar observations can be used to obtain the boundary layer height, in convective conditions.

During summer, the wind speed reaches a minimum value in the free lower troposphere. The average speed in June from 0 to $3 \mathrm{~km}$ is less than $4 \mathrm{~m} / \mathrm{s}$, while during winter it is about $12 \mathrm{~m} / \mathrm{s}$. At the selected day, the wind speed was close to the corresponding monthly average. Consequently, the advection of air masses over the observation site is reduced, and the aerosol concentration can thus be considered a good indicator of the PBL dynamics.

Figure 3 shows the logarithm of the lidar range corrected signal, observed on June 14th; 2010, demonstrating how, even at low aerosol concentrations, the lidar observations allow to determine the layered structure of the boundary layer.

The aerosol distribution clearly shows the temporal evolution of a convective PBL, and the formation of a thin haze layer due to enhanced condensation at its top.

On June 14, the sun never sets at this site, reaching a minimum elevation angle of $12.4^{\circ}$ at 23.12 UTC and a maximum of $34.3^{\circ}$ at 11.12 UTC. In the early hours of the day (00 UTC07 UTC) lidar profiles show the presence of haze and thin stratiform cloud layers in the first $\mathrm{km}$, while in the central part of the day the sun radiation reaches the ground through a broken layer and heats the surface. This is also confirmed by the net radiative balance at the surface, which reaches peaks of $700 \mathrm{~W} / \mathrm{m}^{2}$ around noon, a value compatible with clear sky conditions at that latitude and season. This heat flux determines thus the convective structure observed for the PBL.

After noon, the weakened solar radiance causes the thinning of the mixed layer, which falls under $300 \mathrm{~m}$ at midnight. Low clouds are formed again after 16 UTC, likely due to radiative cooling. 

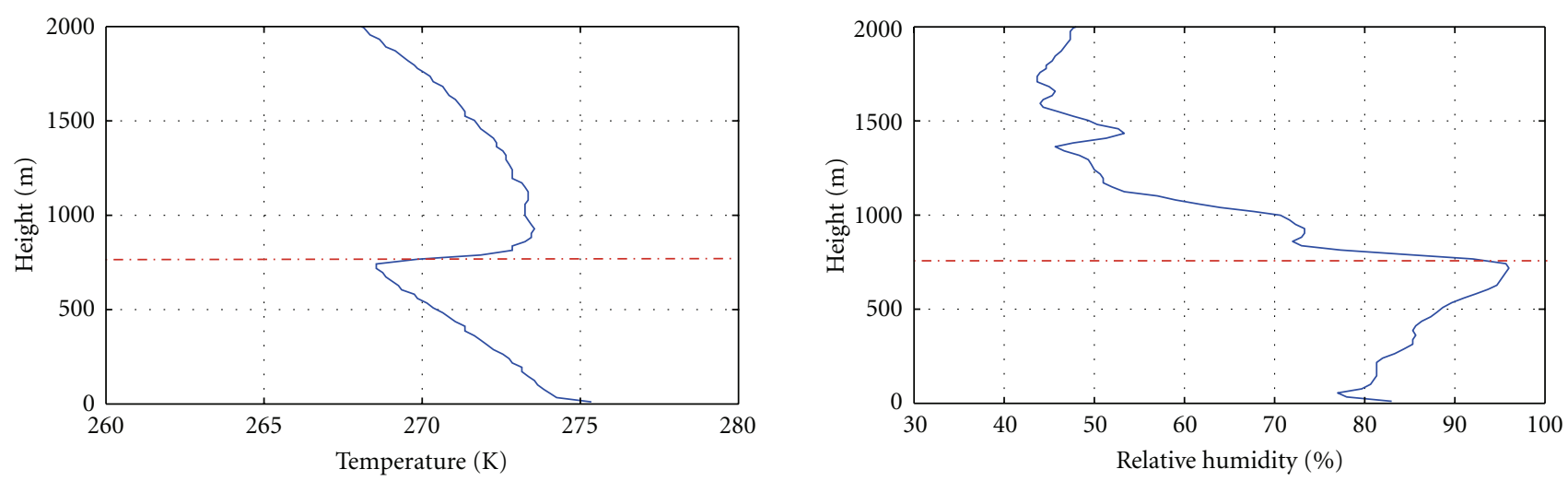

(a)
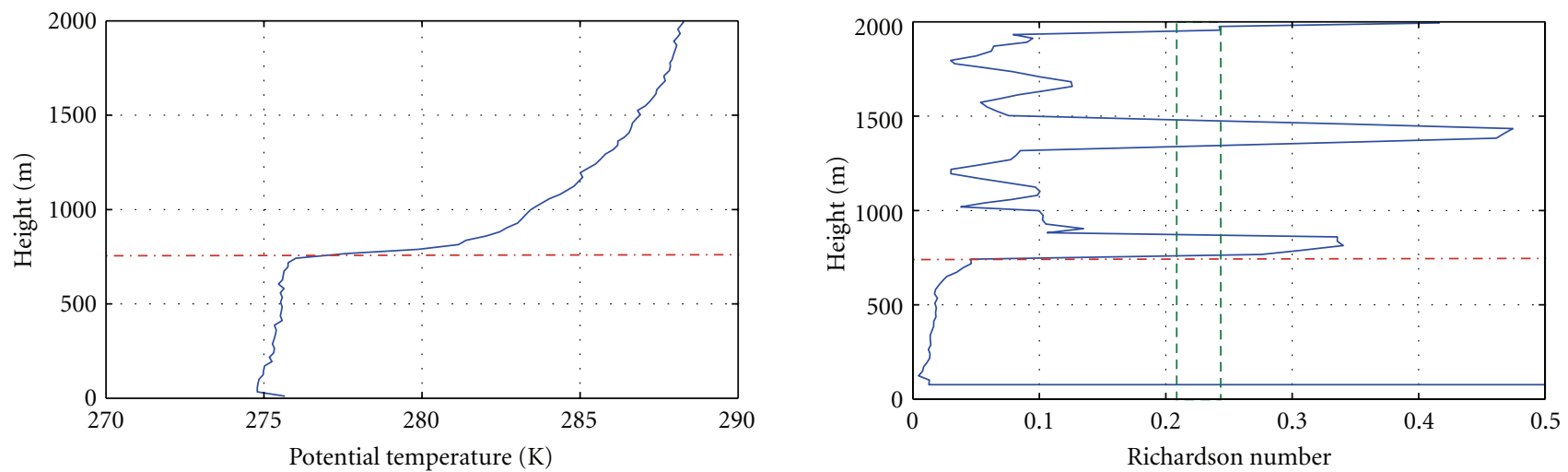

(b)

FIGURE 4: Determination of PBL height from thermodynamic values obtained by a VAISALA RS92 radiosonde. The radiosonde was launched at 12 UTC of the June 14th 2010 from the AWIPEV station of Ny Ålesund. In blue in the upper panel temperature and relative humidity while in the lower panel potential temperature and Richardson number. In dashed red the height of the PBL calculated for potential temperature with the Lapse Rate Method while the vertical green dashed lines on the fourth panel show the range of Richardson numbers between 0.21 and 0.25 .

Figure 4 shows the vertical profiles of temperature, relative humidity, potential temperature, and Richardson number obtained from the 12 UTC radio sounding. The Richardson number is calculated using (1), and a green dotted box identifies the region where the $R_{i b}$ is in the range between 0.21 and 0.25 . The altitude identified with the values between 0.21 and 0.25 is shown as red-dotted line and represents the PBL height.

In Figure 4 in the upper panel temperature and relative humidity profiles are presented, and the relative inflection points are shown. In the lower panel, the potential temperature and the Richardson bulk number profiles are presented as well, together with the PBL height retrieved using these two quantities. These four different estimates are within $20 \mathrm{~m}$, leading to an unambiguous determination of the PBL height by radio sounding. Considering the mean of these four values, the PBL height at 12 UTC can be set to $767 \mathrm{~m}$ above sea level (Figure 5).

This value is consistent with lidar and model estimates, as shown in Figure 5. However, it must be noted that, as explained in Section 2, the attribution of the PBL height to the lidar-derived estimations is still open to question. In fact, it has to be noted that the analysis of lidar produces several layers, which should be interpreted by a visual comparison with the radio sonde measurements and the model output.

The convective behavior of the PBL is confirmed by the model simulation, as will be illustrated below. Because of the difficulties in estimating the subsidence, the $w_{s}$ parameter is often neglected in formula (2). In the shallow mixed layers, the omission of $w_{s}$ is of minor importance in the entire range of meteorological conditions. However, during a high pressure regime, characterized by positive horizontal divergence, the downward directed subsidence velocity increases as the mixed layer evolves and could be comparable in size to the rate at which the mixed layer entrains into the air aloft [40]. In these cases, $w_{s}$ is negative and of the order of some $\mathrm{cm} \mathrm{s}^{-1}$ [41]. Because of the difficulty in estimating $w_{s}$, three values between 3 and $4 \mathrm{~cm} \mathrm{~s}^{-1}$ have been employed. Comparable values were derived for the Antarctica PBL and can be found in the literature [43]. The value of $\gamma$ was derived from the temperature profiles measured by the radio soundings at 12 UTC, obtained in a $100 \mathrm{~m}$ layer above the entrainment layer. The value has been kept constant during the day and equals $0.0025 \mathrm{~K} \mathrm{~m}^{-1}$. 
TABLE 1: Comparison between the advantages and drawbacks of the three approaches to determinate the PBL height.

\begin{tabular}{|c|c|c|}
\hline & Advantages & Disadvantages \\
\hline $\begin{array}{l}\text { Lidar-based gradient } \\
\text { method }\end{array}$ & $\begin{array}{l}\text { High vertical resolution } \\
\text { Continuous measurements } \\
\text { Opportunity to observe aerosol } \\
\text { layers }\end{array}$ & $\begin{array}{l}\text { Lack of overlap at low altitudes } \\
\text { sets a lower limit for PBL height } \\
\text { determination } \\
\text { Needs well-mixed aerosol. } \\
\text { Problems of interpretation with } \\
\text { advected layers }\end{array}$ \\
\hline $\begin{array}{l}\text { Radiosonde-based LR } \\
\text { and RB methods }\end{array}$ & $\begin{array}{l}\text { Large dataset over the world } \\
\text { since radiosondes are routinely } \\
\text { operated } \\
\text { Can be used also in adverse } \\
\text { meteorological conditions }\end{array}$ & $\begin{array}{l}\text { Determination of the PBL height } \\
\text { only in coincidences of the } \\
\text { balloon launch } \\
\text { In case of stable PBL methods } \\
\text { based on potential temperature } \\
\text { are not applicable (or reliable) }\end{array}$ \\
\hline $\begin{array}{l}\text { Batchvarova and } \\
\text { Gryning model }\end{array}$ & $\begin{array}{l}\text { Provides continuous estimate of } \\
\text { the PBL height } \\
\text { Employs only ground based } \\
\text { measurements }\end{array}$ & $\begin{array}{l}\text { Good results only under } \\
\text { convective regimes and clear sky } \\
\text { conditions } \\
\text { Estimate of initialization values } \\
\text { and uncertainties on estimates of } \\
\text { parameters } \\
\text { Turbulent flux measurements are } \\
\text { required } \\
\text { Many approximations in the } \\
\text { physics of PBL processes make } \\
\text { the estimate subject to large } \\
\text { uncertainties }\end{array}$ \\
\hline
\end{tabular}

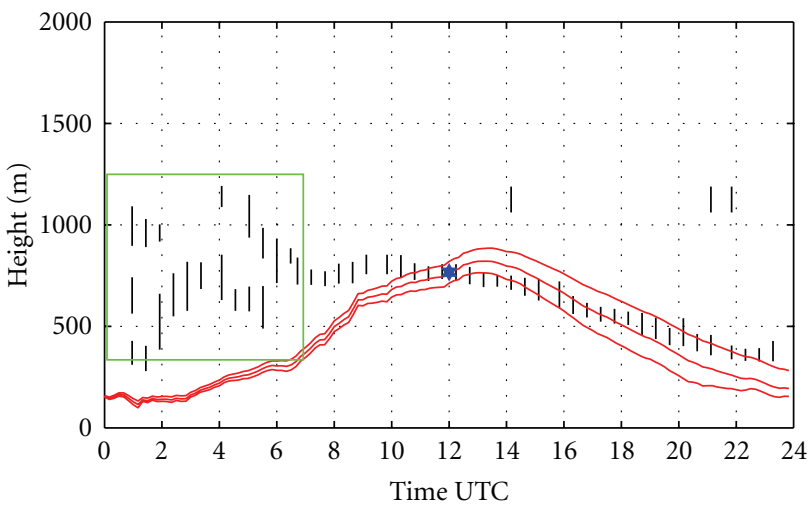

FIgure 5: The PBL height as obtained from the Batchvarova and Gryning model (red line) and radiosonde (blue star) for 14 June 2010. The three red lines correspond to different $w_{s}$ values, as discussed in the text. Black lines indicate the top of the aerosol layers, as detected by the DWT on lidar data, showing the associated indetermination. The aerosol layers enclosed in the green box are associated to hazy layers that likely do not mark off the PBL.

In Figure 5, the behaviour of the PBL height computed using the model for 14 June 2010 is shown as a red line, for the values of $3.0,3.5$, and $4.0 \mathrm{~cm} \mathrm{~s}^{-1}$. The maximum value (always reached at 1330 UTC) ranges between $885 \mathrm{~m}$ and $750 \mathrm{~m}$, depending on the value of $w_{s}$.

The early morning haze does not permit to identify the PBL height by the gradient method with accuracy, since the large aerosol backscatter cross section relative to such layers usually masks the weaker gradients connected to changes in the aerosol vertical distribution. As shown in Figure 5, the Batchvarova and Gryning model predicts a PBL height between $150 \mathrm{~m}$ and $300 \mathrm{~m}$ while the lidar observations show clouds up to $1 \mathrm{~km}$ (green box).

Considering the sensitivity of the model to the values of $w_{s}$, during the evening (19 UTC-24 UTC), the PBL height obtained by the model presents a substantial agreement with the aerosol layer between 400 and $500 \mathrm{~m}$ ASL. Moreover, the wavelet method detects the top of the PBL aerosol/haze, while the model considers the entrainment zone as a null thickness layer.

Considering that the PBL heights determined by the specific methods are based on a different definition of PBL, the comparison of the results obtained, presented in Figure 5, is satisfying.

Table 1 resumes the advantages and drawbacks of each of the three techniques presented in this study, depending on the different meteorological conditions or due to different spatial and temporal resolutions which can be achieved. An integration of the three techniques would provide an accurate determination of the PBL height in different meteorological conditions.

During the spring-summer season, when convective structures of the PBL are frequently observed, the aerosol represents a good tracer to estimate the PBL height. The availability of the lidar data during the day allows to study the daily evolution of the PBL height, while the radio sonde provides only one (or few) measurements per day.

The analysis showed that under suitable conditions the gradient method allows the determination of aerosol layers 
over the Svalbard region. Nevertheless, in case of multiple layers, the attribution of the PBL top still remains uncertain with automated algorithms, and physical constraints have to be applied to determine the PBL height. A methodology to routinely take into account the physics behind the PBL dynamics, assimilating the model prediction in the retrieval algorithm is under development. An example of such approach is described in di Giuseppe et al. [44]. This will likely allow to automatically use Lidar to determine the PBL height and build an extensive data base of PBL height, determined from lidar observations at this site.

\section{Conclusions}

Lidar observations have been used to determine the PBL height at the Arctic site of Ny Ålesund, Svalbard, Norway. The gradient method has been applied to a dataset covering one day (June 14,2010 ) with a convective PBL, typically occurring in the spring early summer season in the Arctic. The logarithm of the range-corrected signal collected by the lidar was processed by a Discrete Wavelet Transform method to determine the inflection points in the aerosol backscatter profile. The aerosol layers found in such way have been compared with radiosonde-based estimate of the PBL height and with the one dimensional zero order Batchvarova and Gryning model.

The results showed a good agreement, considering the differences among the various methods involving several observables and instruments, and different approaches based on distinct physical processes. In favourable cases the gradient method may work automatically providing reliable results, as in the midday period, while more sophisticated algorithms are being developed to deal with more complex conditions.

In spite of the drawbacks inherent to the gradient method and the difficulties in comparing estimates from different approaches, the results obtained encourage to apply this method to a wider data set. A future measurement campaign is planned for 2012, in order to perform an analysis by using the different methods on an extended set of data covering various boundary layer conditions.

\section{Acknowledgments}

The authors wish to thank the station team in Ny Ålesund (AWIPEV) and the logistical support provided by the Department of Earth and Environment of the Italian National Research Council (DTA-CNR). The work was in part funded by the Italian Project PRIN 2007.

\section{References}

[1] J. E. Kay, K. Raeder, A. Gettelman, and J. Anderson, "The boundary layer response to recent arctic sea ice loss and implications for high-latitude climate feedbacks," Journal of Climate, vol. 24, no. 2, pp. 428-447, 2011.

[2] C. Deser, R. Tomas, M. Alexander, and D. Lawrence, "The seasonal atmospheric response to projected Arctic sea ice loss in the late twenty-first century," Journal of Climate, vol. 23, no. 2, pp. 333-351, 2010.

[3] J. Boé, A. Hall, and X. Qu, "Current GCMs' unrealistic negative feedback in the arctic," Journal of Climate, vol. 22, no. 17, pp. 4682-4695, 2009.

[4] P. Seibert, F. Beyrich, S. E. Gryning, S. Joffre, A. Rasmussen, and P. Tercier, "Review and intercomparison of operational methods for the determination of the mixing height," Atmospheric Environment, vol. 34, no. 7, pp. 1001-1027, 2000.

[5] D. S. Covert, A. Wiedensohler, P. Aalto, J. Heintzenberg, P. H. McMurry, and C. Leck, "Aerosol number size distributions from 3 to $500 \mathrm{~nm}$ diameter in the arctic marine boundary layer during summer and autumn," Tellus, Series B, vol. 48, no. 2, pp. 197-212, 1996.

[6] J. Heintzenberg, C. Leck, W. Birmili, B. Wehner, M. Tjernström, and A. Wiedensohler, "Aerosol number-size distributions during clear and fog periods in the summer high Arctic: 1991, 1996 and 2001," Tellus, Series B, vol. 58, no. 1, pp. 41-50, 2006.

[7] T. J. Garrett and C. Zhao, "Increased Arctic cloud longwave emissivity associated with pollution from mid-latitudes," $\mathrm{Na}$ ture, vol. 440, no. 7085, pp. 787-789, 2006.

[8] S. Solomon, D. Qin, M. Manning et al., Eds., The Physical Science Basis. Contribution of Working Group I to the Fourth Assessment Report of the Intergovernmental Panel on Climate Change, Cambridge University Press, New York, NY, USA, 2007.

[9] J. R. McConnell, R. Edwards, G. L. Kok et al., "20th-Century industrial black carbon emissions altered arctic climate forcing," Science, vol. 317, no. 5843, pp. 1381-1384, 2007.

[10] M. C. Serreze, M. M. Holland, and J. Stroeve, "Perspectives on the Arctic's shrinking sea-ice cover," Science, vol. 315, no. 5818, pp. 1533-1536, 2007.

[11] M. Z. Jacobson, "Climate response of fossil fuel and biofuel soot, accounting for soot's feedback to snow and sea ice albedo and emissivity," Journal of Geophysical Research D, vol. 109, no. 21, Article ID D21201, 15 pages, 2004.

[12] J. Hansen and L. Nazarenko, "Soot climate forcing via snow and ice albedos," Proceedings of the National Academy of Sciences of the United States of America, vol. 101, no. 2, pp. 423$428,2004$.

[13] F. Cairo, G. Di Donfrancesco, A. Adriani, L. Pulvirenti, and F. Fierli, "Comparison of various linear depolarization parameters measured by lidar," Applied Optics, vol. 38, no. 21, pp. 4425-4432, 1999.

[14] L. Liu and M. I. Mishchenko, "Constraints on PSC particle microphysics derived from lidar observations," Journal of Quantitative Spectroscopy and Radiative Transfer, vol. 70, no. 4-6, pp. 817-831, 2001.

[15] S. E. Gryning and E. Batchvarova, "Analytical model for the growth of the coastal internal boundary layer during onshore flow," Quarterly Journal, vol. 116, no. 491, pp. 187-203, 1990.

[16] S. Emeis, K. Schäfer, and C. Münkel, "Surface-based remote sensing of the mixing-layer height—a review," Meteorologische Zeitschrift, vol. 17, no. 5, pp. 621-630, 2008.

[17] F. Beyrich, "Mixing height estimation from sodar data-a critical discussion," Atmospheric Environment, vol. 31, no. 23, pp. 3941-3953, 1997.

[18] S. A. Cohn and W. M. Angevine, "Boundary layer height and entrainment zone thickness measured by lidars and windprofiling radars," Journal of Applied Meteorology, vol. 39, no. 8, pp. 1233-1247, 2000.

[19] F. Cairo, G. Di Donfrancesco, L. Di Liberto, and M. Viterbini, "The RAMNI airborne lidar for cloud and aerosol research," 
Atmospheric Measurement Techniques Discussions, vol. 5, pp. 1253-1292, 2012.

[20] M. Haeffelin, F. Angelini, Y. Morille et al., "Evaluation of mixing height retrievals from automatic profiling lidars and ceilometers in view of future integrated networks in Europe," Boundary-Layer Meteorology, pp. 1-27, 2011.

[21] R. M. Endlich, F. L. Ludwig, and E. E. Uthe, "An automatic method for determining the mixing depth from lidar observations," Atmospheric Environment, vol. 13, no. 7, pp. 1051-1056, 1979.

[22] S. H. Melfi, J. D. Spinhirne, S. H. Chou, and S. P. Palm, "Lidar observations of vertically organized convection in the planetary boundary layer over the ocean," Journal of Climate \& Applied Meteorology, vol. 24, no. 8, pp. 806-821, 1985.

[23] B. Hennemuth and A. Lammert, "Determination of the atmospheric boundary layer height from radiosonde and lidar backscatter," Boundary-Layer Meteorology, vol. 120, no. 1, pp. 181-200, 2006.

[24] A. Lammert and J. Bösenberg, "Determination of the convective boundary-layer height with laser remote sensing," Boundary-Layer Meteorology, vol. 119, no. 1, pp. 159-170, 2006.

[25] S. Pal, A. Behrendt, and V. Wulfmeyer, "Elastic-backscatterlidar-based characterization of the convective boundary layer and investigation of related statistics," Annales Geophysicae, vol. 28 , no. 3, pp. 825-847, 2010.

[26] A. Behrendt, S. Pal, F. Aoshima et al., "Observation of convection initiation processes with a suite of state-of-the-art research instruments during COPS IOP 8b," Quarterly Journal of the Royal Meteorological Society, vol. 137, supplement 1, pp. 81-100, 2011.

[27] U. Wandinger and A. Ansmann, "Experimental determination of the lidar overlap profile with Raman lidar," Applied Optics, vol. 41, no. 3, pp. 511-514, 2002.

[28] G. Biavati, G. Di Donfrancesco, F. Cairo, and D. G. Feist, "Correction scheme for close-range lidar returns," Applied Optics, vol. 50, no. 30, pp. 5872-5882, 2011.

[29] I. M. Brooks, "Finding boundary layer top: application of a wavelet covariance transform to lidar backscatter profiles," Journal of Atmospheric and Oceanic Technology, vol. 20, pp. 1092-1105, 2003.

[30] K. J. Davis, N. Gamage, C. R. Hagelberg, C. Kiemle, D. H. Lenschow, and P. P. Sullivan, "An objective method for deriving atmospheric structure from airborne lidar observations," Journal of Atmospheric and Oceanic Technology, vol. 17, no. 11, pp. 1455-1468, 2000.

[31] M. Haij, W. Wauben, and K. Baltink, "Continuous mixing layer height determination using the LD-40 ceilometer: a feasibility study," KNMI Scientific Report, 2007.

[32] A. J. Garrett, "Comparison of observed mixed-layer depths to model estimates using observed temperatures and winds, and MOS forecasts," Journal of Applied Meteorology, vol. 20, no. 11, pp. 1277-1283, 1981.

[33] K. L. Hayden, K. G. Anlauf, R. M. Hoff et al., "The vertical chemical and meteorological structure of the boundary layer in the Lower Fraser Valley during Pacific'93,' Atmospheric Environment, vol. 31, no. 14, pp. 2089-2105, 1997.

[34] D. H. P. Vogelezang and A. A. M. Holtslag, "Evaluation and model impacts of alternative boundary-layer height formulations," Boundary-Layer Meteorology, vol. 81, no. 3-4, pp. 245269, 1996.

[35] L. Menut, C. Flamant, J. Pelon, and P. H. Flamant, "Urban boundary-layer height determination from lidar measurements over the Paris area," Applied Optics, vol. 38, no. 6, pp. 945-954, 1999.
[36] M. Sicard, C. Pérez, A. Comerón, J. M. Baldasano, and F. Rocadenbosch, "Determination of the mixing layer height from regular lidar measurements in the Barcelona Area," in Remote Sensing of Clouds and the Atmosphere VIII, vol. 5235 of Proceedings of SPIE, Barcelona, Spain, 2004.

[37] G. Martucci, R. Matthey, V. Mitev, and H. Richner, "Lidar determination of mixing layer height with high resolution," in Remote Sensing of Clouds and the Atmosphere X, vol. 5979 of Proceedings of SPIE, Brugge, Belgium, 2005.

[38] I. B. Troen and L. Mahrt, "A simple model of the atmospheric boundary layer; sensitivity to surface evaporation," BoundaryLayer Meteorology, vol. 37, no. 1-2, pp. 129-148, 1986.

[39] J. C. King, S. A. Argentini, and P. S. Anderson, "Contrasts between the summertime surface energy balance and boundary layer structure at Dome C and Halley stations, Antarctica," Journal of Geophysical Research D, vol. 111, no. 2, Article ID D02105, 13 pages, 2006.

[40] E. Batchvarova and S. E. Gryning, "An applied model for the height of the daytime mixed layer and the entrainment zone," Boundary-Layer Meteorology, vol. 71, no. 3, pp. 311-323, 1994.

[41] E. Batchvarova and S. E. Gryning, "Applied model for the growth of the daytime mixed layer," Boundary-Layer Meteorology, vol. 56, no. 3, pp. 261-274, 1991.

[42] X. Lee, W. Massman, and B. Law, Handbook of Micrometeorology, Kluwer Academic, Dordrecht, The Netherlands, 2004.

[43] S. Argentini, A. Viola, A. M. Sempreviva, and I. Petenko, "Summer boundary-layer height at the plateau site of Dome C, Antarctica," Boundary-Layer Meteorology, vol. 115, no. 3, pp. 409-422, 2005.

[44] F. Di Giuseppe, A. Riccio, L. Caporaso, G. Bonafè, G. P. Gobbi, and F. Angelini, "Automatic detection of atmospheric boundary layer height using ceilometer backscatter data assisted by a boundary layer model," Quarterly Journal of the Royal Meteorological Society, In press. 

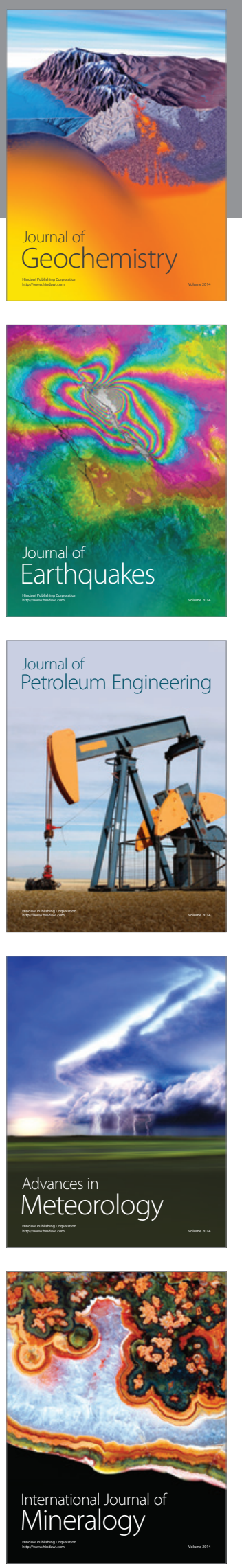
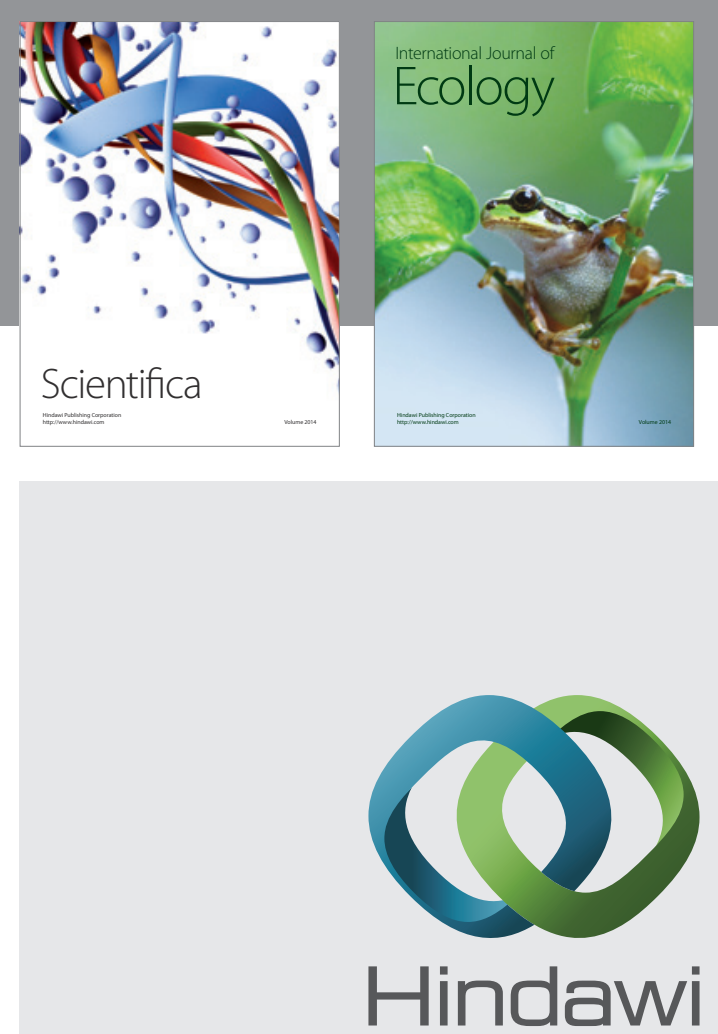

Submit your manuscripts at http://www.hindawi.com
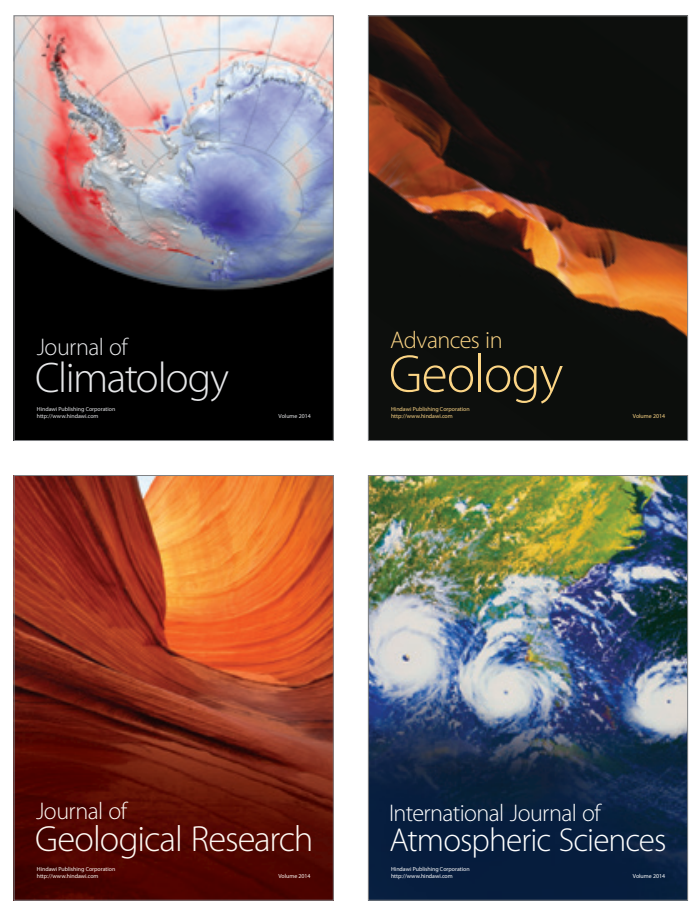
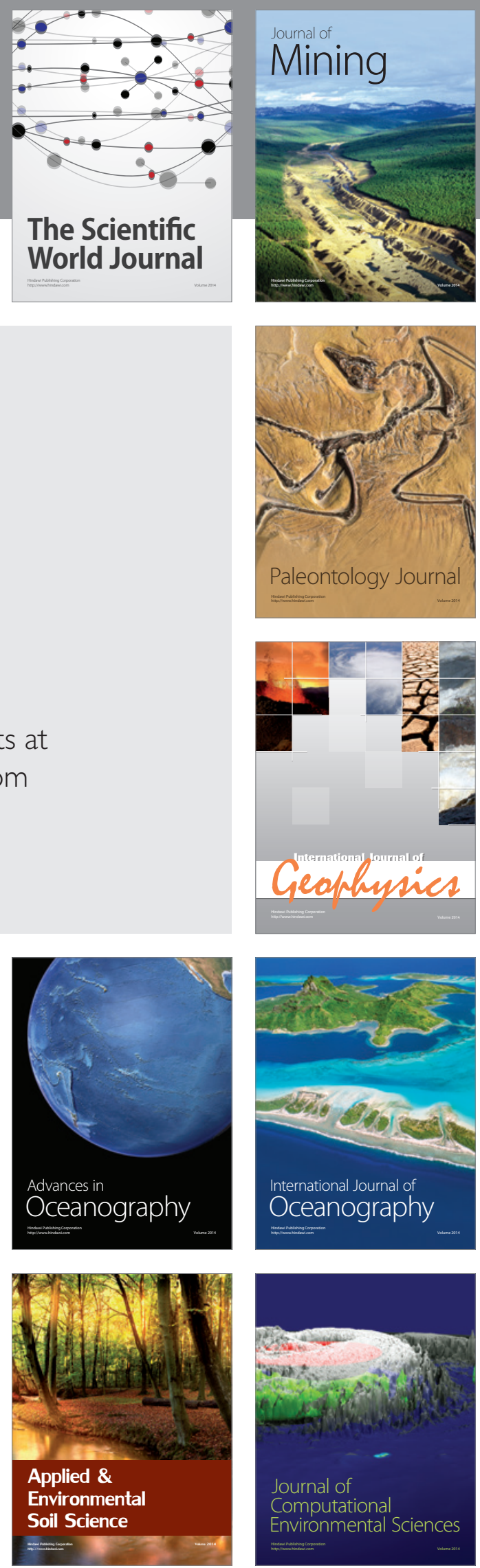